\title{
Attitudes towards and beliefs about nutrition and health among a random sample of adults in the Republic of Ireland and Northern Ireland
}

\author{
John M Kearney ${ }^{1, *}$, Michael J Gibney ${ }^{2}$, Barbara E Livingstone ${ }^{3}$, Paula J Robson ${ }^{3}$, \\ Mairead Kiely ${ }^{4}$ and Karen Harrington ${ }^{2}$ \\ 'Institute of European Food Studies, Trinity College, Dublin 2, Republic of Ireland: ${ }^{2}$ Department of Clinical \\ Medicine, Trinity Centre for Health Sciences, St. James Hospital, Dublin 8, Republic of Ireland: ${ }^{3}$ Northern Ireland \\ Centre, for Diet and Health (NICHE), University of Ulster, Coleraine, Co. Londonderry, BT52 1SA, Northern Ireland: \\ ${ }^{4}$ Nutrition Sciences, Department of Food Science and Technology, University College, Cork, Republic of Ireland
}

\begin{abstract}
Objectives: For effective healthy eating promotion, it is necessary to understand the attitudes towards and beliefs about nutrition of the general public. The objective of this study was to provide data on attitudes towards eating a healthy diet and the perceived need to alter eating habits from a random sample of adults in the Republic of Ireland and in Northern Ireland, using a self-administered questionnaire.

Design: Cross-sectional survey using a self-administered attitudinal questionnaire on beliefs and attitudes to healthy eating.

Setting: The survey was carried out between October 1997 and October 1999 in the Republic of Ireland and in Northern Ireland.

Subjects: A randomly selected sample of 1256 adults from the Republic of Ireland and Northern Ireland completed the attitudinal questionnaire.

Results: A majority of subjects (62\%) perceived that they make conscious efforts to eat a healthy diet either most of the time or quite often, while just over half $(52 \%)$ agreed that they do not need to make changes to their diet as it is healthy enough. Subjects most likely to make conscious efforts to try to eat a healthy diet were females, older subjects (51-64 years) and those with the highest intakes of fruit and vegetables and lowest quartile of fat (\% food energy). When self-assessed adequacy of fruit and vegetables was examined, two-thirds of the total sample felt they ate too little fruit while just one-third felt they ate too little vegetables.

Conclusion: Results of the present study, in general, revealed good agreement between attitude and behaviour with respect to healthy eating. This suggests that people appear to be reasonably accurate at evaluating their own diet in terms of how healthy it is. In terms of the two food groups examined in this study, some optimistic bias was evident for vegetables but not for fruit. It may be useful therefore to assess attitudes and beliefs about healthy eating by way of examining attitudes to such food groups individually.
\end{abstract}

At the International Conference on Nutrition in Rome (1992), there was general agreement that an effective nutrition education programme needs to be based on empirical data and on messages that are targeted to specific groups'. In the mid ' 90 s the largest pan-EU survey on consumer attitudes to food, nutrition and health was carried out in order to provide policy makers and those involved in nutrition education at EU and member state level with data on which to base healthy eating promotion messages ${ }^{2}$. Results from this large quantitative attitudinal study revealed wide demographic and regional variability throughout the European Union (EU) in consumer attitudes to food, nutrition and health, and emphasised the need for targeted nutrition education messages. Traditionally, segments identified in a population for a health promotion campaign have been based on demographic characteristics such as sex, age and social class. However, groups may also be distinguished from one another by their differing attitudes, beliefs and motivations with regard to healthy eating ${ }^{3}$. In order to identify appropriate target groups for nutrition education, it is necessary to examine the influence of socio-demographic 
factors on attitudes towards a healthy diet. Such studies on consumer attitudes to nutrition and diet are a relatively recent area of research. In spite of the numerous studies undertaken to examine the influence of food and nutrients on health, surprisingly few studies have looked at consumers' attitudes to healthy eating. Much of this research has applied theoretical models from the field of psychology to explain dietary behaviour, in particular the theory of reasoned action ${ }^{4}$.

The goal of any nutrition education campaign is to improve the diet of the population. Such campaigns try to achieve this by telling people what they should eat, based on current dietary guidelines, with the assumption being that once the public knows about these guidelines they will adopt them. However, this may be confounded by the fact that subjects may believe that they are already consuming a healthy diet while in fact they may not actually be consuming such a diet ${ }^{5}$. This was shown to be the case in one study in which half of the subjects who believed they were eating a healthy diet were actually not doing so $^{6}$. From a study involving the perceived needs to alter eating habits among 14331 EU subjects, the authors conclude that dietary advice to alter eating habits may not be seen as personally relevant ${ }^{7}$.

At the International Conference on Nutrition, it was also agreed that for nutrition education to be effective, the public should perceive and identify with the importance of appropriate diets and healthy lifestyles ${ }^{8}$. Indeed, the health belief model suggests that one of the determinants of subjects actually making health-related behavioural changes is the perceived need to undertake such an action? ${ }^{9}$. Thus, it may be that in addition to an awareness of the dietary guidelines, an awareness of the need to alter one's diet may be crucial to bring about a change in dietary behaviour. For example, subjects may perceive they do not need to alter their diets as they are already healthy enough (and they are healthy according to current national guidelines) or it may be that subjects perceive their diets to be healthy, even though they may not be. It is not possible to distinguish between these scenarios unless the dietary intakes along with their attitudes can be assessed simultaneously. This study, having such data on both intakes and attitudes, permits an exploration of this issue. With this knowledge it should then be possible to target the nutrition message appropriately to those with differing perceptions about their need to alter their eating habits.

The objective of this study was to provide data on attitudes towards eating a healthy diet and the perceived need to alter eating habits from a random sample of adults in the Republic of Ireland and Northern Ireland, using a self-administered questionnaire. The present study also sought to investigate the relationship between attitudes to healthy eating and behaviour in terms of the quality of the diet regarding fat (\% food energy), fruit and vegetable intake. As the promotion of a healthy diet is likely to be more effective if it is targeted to specific subgroups in the population, another objective was to examine the sociodemographic factors that influence attitudes towards and beliefs about a healthy diet.

\section{Methods}

\section{Survey sample}

For the analysis, the attitudinal component of the North/ South Ireland Food Consumption Survey (NSIFCS) was used. The NSIFCS (using a 7-day estimated food diary) was carried out in the Republic of Ireland and in the Northern Ireland between October 1997 and October 1999. A total of 1379 adults completed the food consumption survey of which 958 were from the Republic of Ireland and 421 were from Northern Ireland. The response rate was $65 \%$ in the Republic and 54\% in the North. Subjects were randomly selected using the electoral register as the sampling frame. Details of sampling and the methods of food intake assessment are described in detail elsewhere $e^{10,11}$.

\section{Attitudinal questionnaire}

The food consumption survey was accompanied by an attitudinal questionnaire that respondents were asked to complete towards the end of the survey. Subjects received the attitudinal questionnaire on day 5 . The questionnaire, which was self-administered, may therefore have been completed any time between day 5 and the final visit (usually day 8). The attitudinal questionnaire consisted of the following three statements relating to healthy eating:

1. I make conscious efforts to try and eat a healthy diet;

2. I try to keep the amount of fat I eat to a healthy amount;

3. I don't need to make changes to my diet as it is healthy enough.

Subjects were asked to select the most appropriate response using a 5-point Likert scale ranging from 'most of the time' to 'hardly ever' for the first two statements and ranging from 'strongly agree' to 'strongly disagree' for the third statement.

\section{Statistics}

Data were analysed by descriptive statistics and the results are shown as percentage of subjects for groups selecting each response. Groups were defined by demographic factors such as sex, age group (three levels), education level (four levels), level of energy reporting ${ }^{12}$, and body mass index (BMI) category ${ }^{13}$. Level of energy reporting was assessed by expressing reported energy intake as a ratio of estimated basal metabolic rate $\left(\mathrm{EI} / \mathrm{BMR}_{\mathrm{est}}\right)$. In addition, responses were given a score to enable comparisons between groups. The scores were given as follows for the first two statements: 
$1=$ hardly ever;

2 = now and again;

3 = quite often;

$4=$ most of the time;

and for the third statement:

1 = strongly disagree;

$2=$ tend to disagree;

$3=$ tend to agree;

$4=$ strongly agree.

The response 'don't know' was not given a score and was therefore not included in the analysis. Differences of scores between groups were examined using one-way analysis of variance (ANOVA) and Scheffe's multiple comparison test $(\alpha=0.05)$. Responses to the three statements were cross-tabulated in order to assess their relationship with one another. Spearman's tho was used as the measure of bivariate correlation for non-parametric data and data with ordered categories.

The attitudes to fruit and vegetables were also examined in this study to determine the level (if any) of optimistic bias for these two food groups. This was done by examining the self-assessed adequacy of the two food groups among those in the lowest and highest quartiles of fruit intake, vegetable intake and fat intake (\% food energy). Subjects assessed the adequacy of their own diet by selecting one of the following responses that they felt was most appropriate to their own intakes (of fruit and of vegetables):

eat about the right amount;

eat too much;

eat too little;

don't eat; and

don't know.

Statistical analysis was carried out using SPSS version 9.0 (SPSS Inc., Chicago, IL).

\section{Results}

A total of 1256 subjects completed the attitudinal questionnaire. This represents $91 \%$ of the total sample that completed the food consumption survey. Out of the total sample completing the attitudinal questionnaire, $62 \%$ of subjects perceived they make conscious efforts to try to eat a healthy diet either most of the time or quite often (Table 1). A similar proportion of subjects perceived that they try to keep the amount of fat they eat to a healthy amount (63\%), while just over half of the sample (52\%) agreed that they do not need to make changes to their diet as it is already healthy enough (strongly agree and tend to agree combined). Mean scores are also given. A high score indicates that a greater proportion of subjects are making conscious efforts to eat healthily most of the time, or are trying to keep the amount of fat in their diet to a healthy amount most of the time, or agree strongly that they don't need to make changes to their diet. A lower mean score was found for the statement 'I don't need to make changes to my diet as it is already healthy enough' $(P<0.05)$ compared with the scores for the other two statements. The responses to the three statements were also cross-tabulated to assess their relationship with one another (data not shown). There was a highly significant correlation between the first two statements (Spearman's rho $=0.68 ; P<0.001)$. The correlation between those making conscious efforts to eat healthily and agreeing that they don't need to make changes to their diet, while less strong (Spearman's rho $=0.37$ ), was highly significant $(P<0.001)$.

Tables 2-4 characterise the different responses to the three statements ('I make conscious efforts to try and eat a healthy diet', 'I try to keep the amount of fat I eat to a healthy amount' and 'I don't need to make changes to my diet as it is healthy enough') according to demographics, BMI category, level of energy reporting $\left(E I / B R_{\text {est }}\right.$ category), smoking status, nutrient (quartiles of fat as \% food energy) intake and food intake (lowest and highest quartiles of fruit and vegetable intakes). Females were more likely to make conscious efforts to try to eat a healthy diet 'most of the time', while males were three times more likely to 'hardly ever' make such conscious efforts to eat a healthy diet $(P<0.05)$ (Table 2). The youngest age group (18-35 years) was less inclined to make conscious efforts to try to eat a healthy diet 'most of the time' compared with the two older age groups.

Table 1 Percentage of subjects selecting responses and the mean score for the three statements 'I make conscious efforts to eat a healthy diet', 'I try to keep the amount of fat I eat to a healthy amount' and 'I don't need to make changes to my diet as it is healthy enough'

\begin{tabular}{|c|c|c|c|c|c|c|c|}
\hline Statement & $n$ & $\begin{array}{l}\text { Most of } \\
\text { the time }\end{array}$ & $\begin{array}{l}\text { Quite } \\
\text { often }\end{array}$ & $\begin{array}{l}\text { Now and } \\
\text { again }\end{array}$ & $\begin{array}{l}\text { Hardly } \\
\text { ever }\end{array}$ & $\begin{array}{l}\text { Don't } \\
\text { know }\end{array}$ & $\begin{array}{l}\text { Mean } \\
\text { score }\end{array}$ \\
\hline \multirow[t]{2}{*}{$\begin{array}{l}\text { I make conscious efforts to try and eat a healthy diet } \\
\text { I try to keep the amount of fat I eat to a healthy amount }\end{array}$} & $\begin{array}{l}1256 \\
1254\end{array}$ & $\begin{array}{l}40 \\
38\end{array}$ & $\begin{array}{l}22 \\
25\end{array}$ & $\begin{array}{l}25 \\
19\end{array}$ & $\begin{array}{l}12 \\
16\end{array}$ & $\begin{array}{r}<1 \\
2\end{array}$ & $\begin{array}{l}2.91^{\mathrm{a}} \\
2.88^{\mathrm{a}}\end{array}$ \\
\hline & $n$ & $\begin{array}{l}\text { Strongly } \\
\text { agree }\end{array}$ & $\begin{array}{l}\text { Tend to } \\
\text { agree }\end{array}$ & $\begin{array}{l}\text { Tend to } \\
\text { disagree }\end{array}$ & $\begin{array}{l}\text { Strongly } \\
\text { disagree }\end{array}$ & $\begin{array}{l}\text { Don't } \\
\text { know }\end{array}$ & $\begin{array}{l}\text { Mean } \\
\text { score }\end{array}$ \\
\hline I don't need to make changes to my diet as it is healthy enough & 1254 & 12 & 40 & 30 & 11 & 7 & $2.57^{b}$ \\
\hline
\end{tabular}

* Mean score calculated using scores assigned to the first four responses to the statements. Subgroups sharing the same superscript are not significantly different within ANOVA using Scheffe's multiple comparison test $(\alpha=0.05)$. 
Table 2 Percentage of subjects selecting responses to the statement 'I make conscious efforts to try to eat a healthy diet' classified by demographics (sex, age, educational achievement), BMI category, level of energy reporting, smoking status and level of fat, fruit and vegetable intakes; mean scores also shown

\begin{tabular}{|c|c|c|c|c|c|c|}
\hline Variable & $n$ & Mean score* & Most of the time & Quite often & Now and again & Hardly ever \\
\hline \multicolumn{7}{|l|}{ Sex } \\
\hline Male & 584 & $2.70^{a}$ & 33 & 22 & 25 & 19 \\
\hline Female & 672 & $3.09^{b}$ & 47 & 22 & 25 & 6 \\
\hline \multicolumn{7}{|l|}{ Age group } \\
\hline $18-35$ years & 490 & $2.60^{\mathrm{a}}$ & 25 & 24 & 35 & 15 \\
\hline $36-50$ years & 473 & $3.04^{\mathrm{b}}$ & 46 & 23 & 21 & 10 \\
\hline 51-64 years & 293 & $3.23^{c}$ & 56 & 19 & 16 & 9 \\
\hline \multicolumn{7}{|l|}{ Education level attained } \\
\hline Primary & 255 & $2.87^{\mathrm{a}}$ & 43 & 17 & 24 & 16 \\
\hline Intermediate & 258 & $2.77^{\mathrm{ab}}$ & 36 & 17 & 31 & 14 \\
\hline Second level & 235 & $2.88^{\mathrm{a}}$ & 39 & 23 & 24 & 14 \\
\hline Third level & 494 & $3.04^{\mathrm{ac}}$ & 42 & 28 & 23 & 8 \\
\hline \multicolumn{7}{|l|}{ BMI category } \\
\hline Normal weight $\left(18.5-24.9 \mathrm{~kg} \mathrm{~m}^{-2}\right)$ & 518 & $2.91^{\mathrm{a}}$ & 41 & 22 & 24 & 13 \\
\hline Overweight $\left(25.0-29.9 \mathrm{~kg} \mathrm{~m}^{-2}\right)$ & 469 & $2.97^{a}$ & 42 & 24 & 23 & 11 \\
\hline Obese $\left(\geq 30.0 \mathrm{~kg} \mathrm{~m}^{-2}\right)$ & 216 & $2.83^{\mathrm{a}}$ & 37 & 20 & 31 & 12 \\
\hline \multicolumn{7}{|l|}{$\mathrm{El} / \mathrm{BMR}_{\mathrm{est}}$ category } \\
\hline Up to 1.2 & 447 & $3.05^{\mathrm{a}}$ & 46 & 22 & 25 & 7 \\
\hline $1.2-1.4$ & 257 & $2.97^{\mathrm{a}}$ & 42 & 23 & 26 & 9 \\
\hline$>1.4$ & 549 & $2.77^{\mathrm{b}}$ & 35 & 22 & 25 & 16 \\
\hline \multicolumn{7}{|l|}{ Smoking status } \\
\hline Current & 411 & $2.55^{a}$ & 27 & 21 & 31 & 20 \\
\hline Ex & 295 & $3.10^{\mathrm{b}}$ & 50 & 19 & 22 & 8 \\
\hline Never & 540 & $3.08^{\mathrm{b}}$ & 46 & 24 & 22 & 8 \\
\hline \multicolumn{7}{|l|}{ Total fat (\% food energy) } \\
\hline Lowest quartile & 312 & $3.40^{\mathrm{a}}$ & 62 & 19 & 15 & 4 \\
\hline Highest quartile & 314 & $2.68^{b}$ & 31 & 19 & 35 & 14 \\
\hline \multicolumn{7}{|l|}{ Fruit intake } \\
\hline Lowest quartile & 308 & $2.36^{a}$ & 22 & 16 & 37 & 24 \\
\hline Highest quartile & 319 & $3.42^{\mathrm{b}}$ & 60 & 24 & 12 & 3 \\
\hline \multicolumn{7}{|l|}{ Vegetable intake } \\
\hline Lowest quartile & 309 & $2.55^{\mathrm{a}}$ & 27 & 21 & 33 & 19 \\
\hline Highest quartile & 312 & $3.30^{\mathrm{b}}$ & 58 & 20 & 17 & 5 \\
\hline
\end{tabular}

* Mean score calculated using scores assigned to responses to the statement. Subgroups sharing the same superscript are not significantly different within ANOVA using Scheffe's multiple comparison test $(\alpha=0.05)$.

One-way ANOVA using the mean scores demonstrates this, with the oldest age group (51-64 years) being more likely to 'make conscious efforts to eat healthy most of the time' compared with the younger subjects $(P<0.05)$. The youngest age group had the lowest mean score (2.60) of any of the factors examined in this table, indicating that they are the least likely group to make efforts to consciously eat healthily.

Those subjects less likely to make conscious efforts to eat a healthy diet were those with an EI/BMR $>1.40$ and current smokers. The highest mean scores were seen among those in the lowest fat (\% food energy) quartile and the highest fruit and vegetable quartiles. Eighty-four per cent of subjects in the highest fruit quartile perceive they made conscious efforts to eat healthily most of the time or quite often compared with just 38\% among the lowest fruit quartile.

Table 3 gives the percentage of subjects selecting responses to the statement 'I try to keep the amount of fat I eat to a healthy amount' according to demographic factors, BMI category, level of energy reporting, smoking status and level of food and nutrient intakes. The mean scores for responses analysed by one-way ANOVA are also shown. A very similar demographic and lifestyle profile emerges for those subjects selecting 'I try to keep the amount of fat I eat to a healthy amount most of the time' as made conscious efforts to eat a healthy diet 'most of the time'. Those subjects who were more likely to watch their fat intake 'most of the time' were females, older subjects (51-64 years), those educated to third level or with a primary level education only, energy reporters with $\mathrm{EI} / \mathrm{BMR}<1.40$, ex- and never smokers, subjects from the lowest quartile of fat intake and those from the highest quartile of fruit intake. The subjects with the highest mean score were those from the lowest fat quartile (mean score $=3.40 ; P<0.05$ ). Obese subjects were less likely to try to reduce the amount of fat to a healthy amount 'most of the time' or 'quite often' compared with normal weight and overweight subjects, though the differences were not significant.

The percentage of subjects agreeing or disagreeing with the statement 'I don't need to make changes to my diet as it is healthy enough' according to demographics, BMI category, level of energy reporting, smoking status and nutrient and food intakes is shown in Table 4. The mean score of agreement is also shown whereby the higher the 
Table 3 Percentage of subjects selecting responses to the statement 'I try to keep the amount of fat I eat to a healthy amount' classified by demographics (sex, age, educational achievement), BMl category, level of energy reporting, smoking status and level of fat, fruit and vegetable intakes; mean scores also shown

\begin{tabular}{|c|c|c|c|c|c|c|}
\hline Variable & $n$ & Mean score* & Most of the time & Quite often & Now and again & Hardly ever \\
\hline \multicolumn{7}{|l|}{ Sex } \\
\hline Male & 583 & $2.67^{a}$ & 33 & 23 & 9 & 23 \\
\hline Female & 671 & $3.05^{b}$ & 43 & 27 & 19 & 10 \\
\hline \multicolumn{7}{|l|}{ Age group } \\
\hline $18-35$ years & 490 & $2.54^{\mathrm{a}}$ & 24 & 28 & 26 & 21 \\
\hline $36-50$ years & 473 & $3.00^{\mathrm{b}}$ & 43 & 26 & 18 & 12 \\
\hline $51-64$ years & 291 & $3.24^{\mathrm{c}}$ & 56 & 21 & 8 & 12 \\
\hline \multicolumn{7}{|l|}{ Education level attained } \\
\hline Primary & 255 & $2.89^{\mathrm{a}}$ & 42 & 21 & 16 & 18 \\
\hline Intermediate & 257 & $2.74^{a b}$ & 34 & 23 & 21 & 19 \\
\hline Secondary & 235 & $2.78^{a}$ & 34 & 28 & 18 & 18 \\
\hline Tertiary & 493 & $2.99^{\mathrm{ac}}$ & 41 & 29 & 19 & 11 \\
\hline \multicolumn{7}{|l|}{ BMI category } \\
\hline Normal weight $\left(18.5-24.9 \mathrm{~kg} \mathrm{~m}^{-2}\right)$ & 515 & $2.86^{a}$ & 38 & 26 & 17 & 17 \\
\hline Overweight $\left(25.0-29.9 \mathrm{~kg} \mathrm{~m}^{-2}\right)$ & 469 & $2.93^{\mathrm{a}}$ & 40 & 26 & 18 & 15 \\
\hline Obese $\left(\geq 30.0 \mathrm{~kg} \mathrm{~m}^{-2}\right)$ & 216 & $2.80^{\mathrm{a}}$ & 35 & 23 & 23 & 27 \\
\hline \multicolumn{7}{|l|}{$\mathrm{El} \mathrm{BMR}_{\mathrm{est}}$ category } \\
\hline Up to 1.2 & 447 & $3.03^{\mathrm{a}}$ & 42 & 28 & 20 & 10 \\
\hline $1.2-1.4$ & 257 & $2.99^{a}$ & 41 & 28 & 16 & 13 \\
\hline$>1.4$ & 547 & $2.70^{\mathrm{b}}$ & 34 & 23 & 19 & 22 \\
\hline \multicolumn{7}{|l|}{ Smoking status } \\
\hline Current & 411 & $2.56^{\mathrm{a}}$ & 26 & 26 & 23 & 23 \\
\hline Ex & 299 & $3.04^{b}$ & 48 & 22 & 16 & 14 \\
\hline Never & 538 & $3.03^{b}$ & 43 & 27 & 17 & 11 \\
\hline \multicolumn{7}{|l|}{ Total fat (\% food energy) } \\
\hline Lowest quartile & 312 & $3.40^{\mathrm{a}}$ & 60 & 23 & 11 & 5 \\
\hline Highest quartile & 314 & $2.58^{\mathrm{b}}$ & 30 & 21 & 25 & 23 \\
\hline \multicolumn{7}{|l|}{ Fruit intake } \\
\hline Lowest quartile & 308 & $2.45^{\mathrm{a}}$ & 25 & 20 & 24 & 27 \\
\hline Highest quartile & 318 & $3.33^{b}$ & 57 & 25 & 12 & 6 \\
\hline \multicolumn{7}{|l|}{ Vegetable intake } \\
\hline Lowest quartile & 309 & $2.53^{a}$ & 26 & 25 & 23 & 24 \\
\hline Highest quartile & 312 & $3.19^{b}$ & 51 & 25 & 15 & 9 \\
\hline
\end{tabular}

* Mean score calculated using scores assigned to responses to the statement. Subgroups sharing the same superscript are not significantly different within ANOVA using Scheffe's multiple comparison test $(\alpha=0.05)$.

score, the stronger the level of agreement with the statement. Those subjects most likely to agree with the statement were male, older subjects (23\% of 51-64 year olds vs. $5 \%$ in the youngest age group agree strongly that they don't need to make changes to their diet as it is healthy enough), subjects with a primary level education only, ex-smokers and subjects in the lowest quartile intake of fat (\% energy from food) and highest quartiles of fruit and of vegetable intakes. The subjects with the highest mean score of agreement were those from the oldest age category (mean score $=2.92 ; P<0.05$ ). High scores were also seen among those in the lowest fat quartile (mean score $=2.79 ; P<0.05$ ) and the highest vegetable (mean score $=2.85 ; P<0.05$ ) and fruit (mean score=2.79; $P<0.05$ ) quartiles as well as those with no formal education (mean score $=2.79 ; P<0.05$ ) (Table 4).

Self-assessed adequacy of fruit and vegetable intake was also examined (Table 5). This was assessed by determining how subjects felt about consuming various levels of fruit and vegetables in the total population and according to level of intake (lowest and highest quartiles) of fat ( $\%$ food energy), fruit $\left(\mathrm{g} \mathrm{day}^{-1}\right)$ and vegetables $\left(\mathrm{g} \mathrm{day}^{-1}\right.$ ) (Table 5). Two-thirds of the total sample perceive that they eat too little fruit, while just one-third perceive that they eat too little vegetables. A similar difference was seen in the proportion of the total sample who perceive they eat about the right amount of fruit and of vegetables, with just $28 \%$ of the sample believing that they eat the right amount of fruit compared with $62 \%$ believing they eat the right amount of vegetables. Those in the highest quartiles of fruit intake were more likely to perceive that they were eating the right amount (59\%) compared with those in the lowest quartile of fruit intake (7\%). Furthermore, those in the lowest fruit intake quartile were more likely to select 'eat too little' (83\%) compared with $37 \%$ of the highest fruit intake quartile. A higher proportion of those in the highest quartile of fat $(\%$ food energy) and those in the lowest quartile of vegetable intake selected 'eat too little fruit' compared with those in the lowest quartile of fat intake and those in the highest quartile of vegetable intake $(P<0.05)$. More subjects $(75 \%)$ in the highest quartile of vegetable intake perceive that they eat about the right amount of vegetables compared with those in the lowest quartile of vegetable intake (43\%) $(P<0.001)$ (Table 5). Fewer subjects perceive they 'eat too little vegetables' among those in 
Table 4 Percentage of subjects who agree or disagree with the statement 'I don't need to make changes to my diet as it is healthy enough' classified by demographics (sex, age, educational achievement), BMl category, level of energy reporting, smoking status and level of fat, fruit and vegetable intakes; mean scores also shown

\begin{tabular}{|c|c|c|c|c|c|c|c|}
\hline Variable & $n$ & $\begin{array}{l}\text { Mean } \\
\text { score }\end{array}$ & $\begin{array}{l}\text { Strongly } \\
\text { agree }\end{array}$ & $\begin{array}{l}\text { Tend to } \\
\text { agree }\end{array}$ & $\begin{array}{l}\text { Tend to } \\
\text { disagree }\end{array}$ & $\begin{array}{l}\text { Strongly } \\
\text { disagree }\end{array}$ & $\begin{array}{l}\text { Don't } \\
\text { know }\end{array}$ \\
\hline \multicolumn{8}{|l|}{ Sex } \\
\hline Male & 83 & $2.63^{a}$ & 13 & 41 & 28 & 9 & 8 \\
\hline Female & 71 & $2.52^{\mathrm{b}}$ & 10 & 40 & 32 & 12 & 6 \\
\hline \multicolumn{8}{|l|}{ Age group } \\
\hline 18-35 years & 490 & $2.34^{a}$ & 5 & 26 & 27 & 14 & 8 \\
\hline $36-50$ years & 473 & $2.57^{b}$ & 11 & 44 & 20 & 10 & 5 \\
\hline $51-64$ years & 291 & $2.92^{c}$ & 23 & 43 & 20 & 5 & 8 \\
\hline \multicolumn{8}{|l|}{ Education level attained } \\
\hline Primary & 255 & $2.79^{a}$ & 21 & 38 & 23 & 9 & 10 \\
\hline Intermediate & 257 & $2.44^{\mathrm{b}}$ & 7 & 41 & 29 & 14 & 9 \\
\hline Secondary & 235 & $2.56^{\mathrm{b}}$ & 12 & 38 & 33 & 9 & 8 \\
\hline Tertiany & 493 & $2.53^{b}$ & 9 & 43 & 34 & 10 & 4 \\
\hline \multicolumn{8}{|l|}{ BMI category } \\
\hline Normal weight $\left(18.5-24.9 \mathrm{~kg} \mathrm{~m}^{-2}\right)$ & 515 & $2.69^{a}$ & 10 & 49 & 28 & 6 & 7 \\
\hline Overweight $\left(25.0-29.9 \mathrm{~kg} \mathrm{~m}^{-2}\right)$ & 469 & $2.52^{\mathrm{b}}$ & 11 & 37 & 34 & 10 & 7 \\
\hline Obese $\left(\geq 30.0 \mathrm{~kg} \mathrm{~m}^{-2}\right)$ & 216 & $2.34^{\mathrm{b}}$ & 13 & 29 & 30 & 22 & 6 \\
\hline \multicolumn{8}{|l|}{$\mathrm{El} / \mathrm{BMR}_{\mathrm{est}}$ category } \\
\hline Up to 1.2 & 447 & $2.54^{\mathrm{a}}$ & 14 & 38 & 28 & 15 & 4 \\
\hline $1.2-1.4$ & 257 & $2.55^{\mathrm{a}}$ & 9 & 42 & 34 & 8 & 8 \\
\hline$>1.4$ & 547 & $2.60^{\mathrm{a}}$ & 11 & 42 & 31 & 8 & 9 \\
\hline \multicolumn{8}{|l|}{ Smoking status } \\
\hline Current & 411 & $2.46^{a}$ & 8 & 37 & 33 & 12 & 10 \\
\hline Ex & 299 & $2.68^{b}$ & 16 & 42 & 28 & 9 & 5 \\
\hline Never & 538 & $2.59^{b}$ & 12 & 42 & 29 & 10 & 6 \\
\hline \multicolumn{8}{|l|}{ Total fat (\% food energy) } \\
\hline Lowest quartile & 312 & $2.82^{\mathrm{a}}$ & 19 & 45 & 24 & 6 & 6 \\
\hline Highest quartile & 314 & $2.45^{\mathrm{b}}$ & 9 & 36 & 37 & 11 & 7 \\
\hline \multicolumn{8}{|l|}{ Fruit intake } \\
\hline Lowest quartile & 308 & $2.32^{\mathrm{a}}$ & 6 & 33 & 33 & 17 & 10 \\
\hline Highest quartile & 318 & $2.79^{\mathrm{b}}$ & 17 & 48 & 25 & 6 & 4 \\
\hline \multicolumn{8}{|l|}{ Vegetable intake } \\
\hline Lowest quartile & 309 & $2.39^{\mathrm{a}}$ & 8 & 33 & 36 & 14 & 8 \\
\hline Highest quartile & 311 & $2.85^{b}$ & 17 & 51 & 23 & 4 & 5 \\
\hline
\end{tabular}

- Mean score calculated using responses to the statement. Subgroups sharing the same superscript are not significantly different within ANOVA using Scheffe's multiple comparison test $(\alpha=0.05)$.

the lowest quartile of vegetable intake (51\%) compared with the number of subjects believing they 'eat too little fruit' among those in the lowest quartile of fruit intake $(83 \%)$.
Figure 1 illustrates the striking differences in attitudes to healthy eating according to intake level of fruit, vegetables and fat (\% food energy). Those subjects in the highest quartiles of fruit and of vegetables and in the

Table 5 Percentage of subjects selecting one of five attitudinal responses to consumption of fruit and vegetables (self-assessed adequacy) among those in the lowest and highest quartiles of total fat (\% food energy), fruit $(\mathrm{g})$ and vegetables $(\mathrm{g})$ intakes

\begin{tabular}{|c|c|c|c|c|c|c|}
\hline & $n$ & Eat about the right amount & Eat too much & Eat too little & Don't eat & Don't know \\
\hline \multicolumn{7}{|l|}{ Fruit } \\
\hline Lowest fruit quartile & 308 & 7 & - & 83 & 8 & 2 \\
\hline Highest fruit quartile & 317 & 59 & 2 & 37 & - & 2 \\
\hline Lowest fat quartile & 311 & 42 & 2 & 54 & 2 & - \\
\hline Highest fat quartile & 313 & 19 & - & 73 & 6 & 2 \\
\hline Lowest vegetable quartile & 308 & 18 & 1 & 74 & 5 & 2 \\
\hline Highest vegetable quartile & 310 & 38 & 2 & 56 & 2 & 2 \\
\hline Total & 1252 & 28 & 1 & 66 & 3 & 2 \\
\hline \multicolumn{7}{|l|}{ Vegetables } \\
\hline Lowest vegetable quartile & 309 & 43 & 1 & 51 & 4 & 1 \\
\hline Highest vegetable quartile & 312 & 75 & 3 & 22 & - & - \\
\hline Lowest fat quartile & 312 & 66 & 3 & 29 & 2 & - \\
\hline Highest fat quartile & 314 & 59 & 2 & 38 & 1 & - \\
\hline Lowest fruit quartile & 397 & 52 & 2 & 43 & 3 & - \\
\hline Highest fruit quartile & 319 & 69 & 3 & 27 & - & 1 \\
\hline Total & 1255 & 62 & 2 & 34 & 1 & 1 \\
\hline
\end{tabular}


Low-fat, high-fruit, high-veg

$\square$ High-fat, low-fruit, low-veg

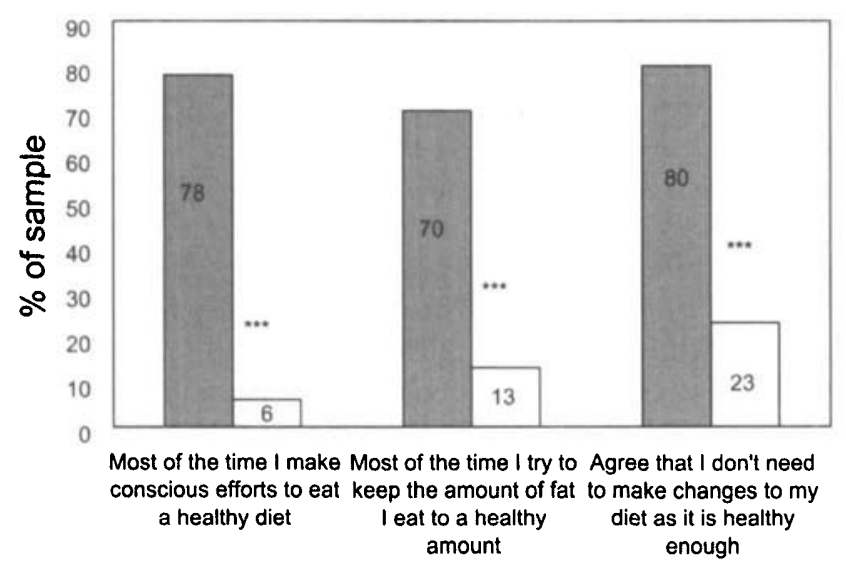

Fig. 1 The percentage of subjects selecting each of three statements according to whether they are in the high-fat, lowfruit, low-vegetable group or the low-fat, high-fruit and highvegetable group. ${ }^{\star * *}$ denotes $P<0.001$ (chi $^{2}$ analysis)

lowest quartile of fat (\% food energy) were more likely 'to make conscious efforts to try to eat a healthy diet: most of the time', 'to try to keep the amount of fat they eat to a healthy amount: most of the time' and 'to agree I don't need to make changes to my diet as it is healthy enough' compared with those from the highest quartile of fat intake (\% food energy) and lowest quartiles of fruit and of vegetable intakes $(P<0.001)$.
The demographic characteristics, levels of energy reporting, BMI category and smoking status among high fruit, high vegetable, low fat consumers (that is among subjects in the highest quartiles of fruit and of vegetables and lowest quartile of fat (\% food energy)) versus low fruit, low vegetable and high fat consumers and the total population are shown in Table 6. Compared with the demographic profile of the total population, subjects in the low-fat, high-fruit, high-vegetables groups were more likely to be older $39 \%$ were in the oldest age group compared with $24 \%$ in the general population). The sex and education profiles were similar to the total population. There were more subjects with EI/BMR est $_{\text {ratio less }}$ than 1.20 ( $44 \%$ vs. $35 \%$ in the general population). The high-fat, low-fruit, low-vegetables group is most strongly represented by the youngest age group (58\%), smokers ( $59 \%$ vs. $35 \%$ in the general population) and by a higher proportion of obese subjects ( $24 \%$ vs. $18 \%$ in the general population). It is under-represented by those with no formal education and those educated to third level when compared with the general population profile for education level attained.

\section{Discussion}

Results from this study found that $62 \%$ of respondents perceive that they make conscious efforts to try and eat a healthy diet either 'most of the time' or 'quite often'. Very similar proportions are trying to keep the amount of fat in

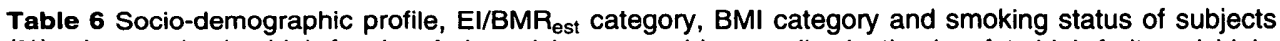
(\%) who are in the high-fat, low-fruit and low-vegetable quartile, in the low-fat, high-fruit and highvegetable quartile, and in the total population

\begin{tabular}{|c|c|c|c|}
\hline & \multicolumn{2}{|c|}{ Quartile } & \multirow[b]{2}{*}{$\begin{array}{l}\text { Total population } \\
\quad(n=1379)\end{array}$} \\
\hline & $\begin{array}{l}\text { High-fat, low-fruit, } \\
\text { low-veg }(n=50)\end{array}$ & $\begin{array}{l}\text { Low-fat, high-fruit, } \\
\text { high-veg }(n=67)\end{array}$ & \\
\hline \multicolumn{4}{|l|}{ Sex } \\
\hline Male & 50 & 48 & 48 \\
\hline Female & 50 & 52 & 52 \\
\hline \multicolumn{4}{|l|}{ Age group } \\
\hline $18-35$ years & 58 & 15 & 38 \\
\hline $36-50$ years & 34 & 46 & 38 \\
\hline $51-64$ years & 8 & 39 & 24 \\
\hline \multicolumn{4}{|c|}{ Education level attained } \\
\hline Primary & 15 & 23 & 21 \\
\hline Intermediate & 32 & 15 & 21 \\
\hline Secondary & 28 & 22 & 19 \\
\hline Tertiary & 25 & 40 & 39 \\
\hline \multicolumn{4}{|l|}{$\mathrm{El} / \mathrm{BMI} \mathrm{esst}_{\text {category }}$} \\
\hline Up to 1.20 & 39 & 44 & 35 \\
\hline $1.20-1.40$ & 18 & 27 & 21 \\
\hline$>1.40$ & 43 & 29 & 44 \\
\hline \multicolumn{4}{|l|}{ BMI category } \\
\hline Underweight & - & - & 1 \\
\hline Normal weight & 41 & 42 & 42 \\
\hline Overweight & 35 & 42 & 39 \\
\hline Obese & 24 & 16 & 18 \\
\hline \multicolumn{4}{|l|}{ Smoking status } \\
\hline Current & 59 & 6 & 33 \\
\hline Ex & 14 & 41 & 24 \\
\hline Never & 27 & 53 & 43 \\
\hline
\end{tabular}


their diet to a healthy amount 'most of the time' or 'quite often' (63\%). Somewhat fewer agree (strongly or tend to) that they do not need to make changes to their diet as it is healthy enough (52\%). Such results appear to suggest that the majority of subjects in this sample from the Republic of Ireland and the North of Ireland perceive themselves to be conscious of what they eat, in trying to eat a healthy diet and trying to reduce the amount of fat in their diet. In an earlier study of consumer attitudes to food, nutrition and health among 1000 Irish adults, 'trying to eat healthy' was selected among the top five influences on food choice $^{14}$.

People may be slow to change their eating habits for a number of reasons. It may be due to a lack of knowledge $^{15}$. Social factors may also present difficulties for people trying to make changes to their diet ${ }^{16}$. People may be resistant to changing their diet owing to a lack of interest in nutrition. Indeed, resistance to change was found to be a common perceived barrier to healthy eating among EU subjects ${ }^{15}$. Another and potentially serious barrier to change may be the fact that people do not perceive the need to change, believing their own diet is already healthy enough, i.e. optimistic bias ${ }^{7,17,18}$.

In a recent study looking at the perceived need to alter eating habits among Irish adults, it was found that $66 \%$ of subjects agreed they did not need to change their diet as it was already healthy enough ${ }^{7}$. The authors suggested that a certain degree of optimistic bias may be present in which subjects do not perceive the need to change their diets, believing them to be healthy enough compared with 'others' around them. For this reason dietary advice may then not be personally relevant to those subjects ${ }^{7}$. However, as food intakes had not been assessed, one cannot rule out the possibility that those subjects saying their diet was already healthy enough were correct in that assumption. Indeed, Cotugna et al. ${ }^{17}$ believe that such optimistic bias may represent a significant barrier to dietary change. Among a US national sample of 22040 respondents from the National Health Interview Survey, they found that two-thirds of the sample reported making no dietary changes. One of the main reasons for this is that respondents did not perceive the need to change, believing their diet to be already healthy enough. Similarly, among a sample of English subjects, threequarters of them reported making no dietary change for the same reason ${ }^{6}$.

Since food intake was also assessed in this study it is possible to link behaviour and attitudes among the same respondents. Thus the issue of whether respondents are justified in their complacency with respect to the healthiness of their diets can be explored. Results from this study revealed high levels of agreement between those reporting healthier diets (defined as being in the lowest quartile of fat intake (\% food energy) and the highest quartiles of fruit intake and of vegetable intake) and those selecting the response option 'most of the time' to the statements: 'I make conscious efforts to try and eat a healthy diet' and 'I try to keep the amount of fat I eat to a healthy amount'. Furthermore, it was those subjects with the less healthy diet with respect to fat, fruit and vegetables (as defined above) who were less likely to agree they did not need to make changes to their diet as it was already healthy enough. This suggests that people's attitudes and behaviour are closely related and that people appear to be quite accurate at evaluating their own diet in terms of how healthy it is. This seems to be especially true in the case of fruit intake, with the majority of subjects $(83 \%)$ in the lowest quartile of fruit intake perceiving they eat too little fruit and only $7 \%$ perceiving they eat about the right amount. Thus, in the case of fruit intake, optimistic bias does not appear to be a serious barrier for dietary change: even among those in the highest quartile of fruit intake, $37 \%$ perceived they eat too little fruit. In an earlier study of consumer attitudes among 1000 Irish adults, over $90 \%$ of respondents believed that people in general should eat more fruit and vegetables ${ }^{7}$. This is considerably higher than the levels found in the present study where $66 \%$ of subjects perceived they should eat more fruit and $34 \%$ perceived they should eat more vegetables. This difference between what people believe others should consume and what they themselves should consume may indicate a certain degree of optimistic bias, particularly with respect to vegetable intake. To promote higher consumption patterns of vegetables, an important first step would be to make people aware of their low personal intakes and of their consequent need to consume more. In the case of fruit intake, it may be more a question of overcoming the resistance to change among those who are aware that they consume too little.

A number of other studies have explored both attitudes and behaviour either in relation to fat intake $e^{6,19-21}$ or fruit and vegetable intake ${ }^{22-25}$. Shepherd and Stockley ${ }^{19}$ found that a person's own feelings towards the consumption of a type of food (high in fat) was a good predictor of actual consumption level. However, in a more recent study involving a mailed questionnaire on attitudes and beliefs regarding low-fat diets sent to 2000 consumers in the UK, no consistent differences in attitudes were found between those in the highest fat tertile versus the lowest fat tertile $^{20}$. In that study, regardless of fat intake level (as ascertained through the mailed questionnaire), the majority of subjects felt that their diet was healthy and was not high in fat. The response rate to the questionnaire in this study, however, was low (33\%) and of these, even less were correct and thereby of use in the study (20\%). Using a similar instrument to examine attitudes to fat and fibre among adults in Northern Ireland, Barker et al. ${ }^{26}$ achieved a much greater response rate using an interview-assisted questionnaire $(76 \%)$.

Lechner and $\mathrm{Brug}^{23}$ evaluated fruit and vegetable intake in a sample of 367 Dutch adults using two methods 
of intake assessment (a food-frequency method and subject's own self-assessment) and found that subjects rated their own intake as much higher than their estimated actual intake. In this study, subjects rated their consumption on a 5-point scale from very low to very high. Such self-assessment of fruit and vegetable intakes is not quite the same measure as self-assessed adequacy of fruit and vegetable intake that was looked at in the present study. In another study involving a sample of 453 Australian adults in which self-assessed adequacy of fruit and vegetable intake was examined, it was found to be significantly associated with mean intakes of fruit and vegetables assessed by means of a food-frequency questionnaire $^{22}$. The study also found that quite a high proportion of people with low fruit and vegetable intakes assessed their intake as 'about right'. The results from our study were similar to the Australian study in that close agreement was found between self-assessed adequacy of fruit and vegetable intake and mean intakes of fruit and of vegetable intake in the lowest and highest quartiles. However, in our study, fruit and vegetables were examined individually, and self-assessment adequacy of these two food groups differed considerably among those with the lowest and highest intakes of both fruit and vegetables. Just $7 \%$ of subjects in the lowest fruit quartile perceive they eat about the right amount, while 91\% perceive they eat too little or do not eat fruit at all. This contrasts with the self-assessed adequacy of vegetable intake among those in the lowest vegetable quartile. In this instance quite a high proportion perceive that they eat about the right amount (43\%), while only $51 \%$ perceive they eat too little. Thus, there appears to be an element of optimistic bias with respect to vegetable intake but not fruit intake. These results suggest that, contrary to most studies on attitudes to fruit and vegetables in which they tend to be aggregated, it may be more appropriate to examine the two individually. The results also indicate that different strategies may be needed in healthy eating campaigns for promoting fruit and vegetables separately.

The results of this study showed that females, older subjects and those with a primary or third level education were more likely to make conscious efforts to try to eat healthy diets. These were also the same groups who were more likely to agree that they did not need to make changes to their diet as it was already healthy enough. Subjects with a primary level education only were predominantly in the oldest age group and so after controlling for age (results not shown) those having only a primary level education were no longer more likely to make conscious efforts to try to eat healthier compared with other education levels. Such a demographic profile for those that are more health-conscious in terms of diet has been shown in a number of earlier studies. Lennernas et al. ${ }^{14}$ found in a sample of $14331 \mathrm{EU}$ adults that females and older and more educated subjects were more likely than other subjects to select 'trying to eat healthy' as an important perceived influence to food choice. In another study involving Norwegian adults, it was found that - in line with theories about women's higher health consciousness - women were more likely to report dietary changes that corresponded with the dietary recommendations $^{27}$. Low consumers of fruit and vegetables were more likely to be male, young and current smokers. This concurs with the results of Thompson et al. ${ }^{25}$, who assessed the demographic, knowledge, attitudinal and behavioural characteristics of respondents with low and high fruit and vegetable intakes of 5553 English adults in a cross-sectional survey. The authors suggested that the impact of knowledge might be less important than attitudes regarding a healthy diet in characterising low fruit and vegetable consumers ${ }^{25}$. In this study attitudes to healthy eating varied widely according to level of intake of fruit, vegetables and fat (\% food energy). The high fat consumers and those with low intakes of fruit and of vegetables were much less likely to make a conscious effort to eat healthily than those in the lowest fat quartile and those having the highest intakes of fruit and vegetables. Indeed, attitudes were more strongly influenced by consumption level (of fruit and vegetables) than by socio-demographic factors such as age sex and education level.

\section{Conclusion}

Results of the present study, in general, reveal good agreement between attitudes and behaviour with respect to healthy eating. This suggests that people's attitudes and behaviour are closely related and that people appear to be quite objective in evaluating their own diet in terms of how healthy it is. Looking at the two food groups examined in this study, some optimistic bias was evident for vegetables but not for fruit. Determining the attitudes of people towards their diet and to particular foods may be useful in nutrition education for identifying target groups for whom specific nutrition messages would be appropriate. The main challenges for bringing about dietary change may be due both to optimistic bias (in the case of vegetables) or a resistance to change (in the case of fruit). It may be useful (more appropriate) therefore to assess attitudes and beliefs about healthy eating by way of examining attitudes to such food groups individually.

\section{References}

1 FAO/WHO. International Conference on Nutrition. Major Issues for Nutrition Strategies. Rome: United Nations Food and Agriculture Organisation/World Health Organization, 1992.

2 Gibney MJ, Kearney M, Kearney JM. Introduction - IEFS pan-EU survey of consumer attitudes to food, nutrition and health. Eur. J. Clin. Nutr. 1997; 51: S2.

3 Contento IR, Michela JL, Goldberg CJ. Food choice among adolescents: population segmentation by motivations. $J$. Nutr. Educ. 1988; 20: 289-98. 
4 Fishbein M, Ajzen I. Belief, Attitude, Intention and Bebaviour: An Introduction to Theory and Research. Reading, MA: Addison Wesley, 1975.

5 Worsley A, Crawford D. Awareness and compliance with the Australian dietary guidelines: a descriptive study of Melbourne residents. Nutr. Res. 1985; 5: 1291-308.

6 Margetts BM, Thompson RL, Speller V, McVey D. Factors which influence 'healthy' eating patterns: results from the 1993 HEA Health and Lifestyle Survey in England. Public Health Nutr. 1998; 1: 193-8.

7 Kearney M, Gibney MJ, Martinez JA, de Almeida MDV, Friebe D, Zunft HJF, Widhalm K, Kearney JM. Perceived need to alter eating habits among representative samples of adults from all member states of the European Union. Eur.J. Clin. Nutr. 1997; 51: S30-5.

8 FAO/WHO. International Conference on Nutrition. Nutrition and Development - A Global Assessment. Rome: United Nations Food and Agriculture Organisation/World Health Organization, 1992.

9 Janz NK, Becker MH. The health belief model; a decade later. Health Educ. Q. 1984; 11 : 1-47.

10 Kiely M, Flynn A, Harrington KE, Robson PJ, Cran G. Sampling description and procedures used to conduct North/South Ireland Food Consumption Survey. Public Health Nutr. 2001; 4(5A): 1029-35.

11 Harrington KE, McGowan MJ, Kiely M, Robson PJ, Livingstone MBE, Morrissey PA, Gibney MJ. Macronutrient intakes and food sources in Irish adults: findings of the North/South Ireland Food Consumption Survey. Public Health Nutr. 2001; 4(5A): 1051-60.

12 McGowan MJ, Harrington KE, Kiely M, Robson PJ, Livingstone MBE, Gibney MJ. An evaluation of energy intakes and the ratio of energy intake to estimated basal metabolic rate $\left(E I / B_{\text {B }}\right.$ est $)$ in the North/South Ireland Food Consumption Survey. Public Health Nutr. 2001; 4(5A): 1043-50.

13 International Obesity Task Force. Obesity: Preventing and Managing the Global Epidemic. Geneva: World Health Organization, 1998.

14 Lennernas M, Fjellstrom C, Becker W, Giachetti I, Schmitt A, Remaut de Winter AM, Kearney $M$. Influences on food choice perceived to be important by nationally-representative samples of adults in the European Union. Eur. J. Clin. Nutr. 1997; 51: S8-15.
15 Lappalainen R, Saba A, Holm L, Mykkanen H, Gibney MJ. Difficutlies in trying to eat healthier; descriptive analysis of perceived barriers for healthy eating. Eur. J. Clin. Nutr. 1997; 51: S36-40.

16 Mennel S, Murcott A, van Otterloo AH. The Sociology of Food: Eating, Diet and Culture. London: Sage Publications, 1992; 1-150.

17 Cotugna N, Subar AF, Heimendinger J, Kahle JL. Nutrition and cancer prevention - knowledge, beliefs, attitudes and practices. The 1987 National Health Interview Survey. $J$. Am. Diet. Assoc. 1992; 92: 963-8.

18 Sparks P, Shepherd R. Public perceptions of the potential hazards associated with food production and food consumption: an empirical study. Risk Anal. 1994; 14: 799-806.

19 Shepherd R, Stockley L. Fat consumption and attitudes towards food with a high fat content. Hum. Nutr. Appl. Nutr. 1985; 39: 615-9.

20 Lloyd HM, Paisley CM, Mela DJ. Changing to a low fat diet: attitudes and beliefs of UK consumers. Eur. J. Clin. Nutr. 1993; 47: 361-73.

21 Brug J, van Assema P, Kok G, Lenderink T, Glanz K. Selfrated dietary intake: association with objective assessment of fat, psychosocial factors and intention to change. J. Nutr. Educ. 1994; 26: 218-23.

22 Brug J, Lechner L, De Vries H. Psychosocial determinants of fruit and vegetable consumption. Appetite 1995; 25: 285-96.

23 Lechner L, Brug J. Consumption of fruit and vegetables: how to motivate the population to change their behaviour. Cancer Lett. 1997; 114: 335-6.

24 Radimer KL, Harvey P, Lytle L. Correspondence of selfreported fruit and vegetable intake with dietary intake data. Aust. NZ J. Public Health 1997; 21: 703-10.

25 Thompson RL, Margetts BM, Speller VM, McVey D. The Health Education Authority's health and lifestyle survey 1993: who are the low fruit and vegetable consumers? $J$. Epidemiol. Community Health 1999; 53: 294-9.

26 Barker ME, Thompson KA, McClean SI. Attitudinal dimensions of food choice and nutrient intake. Br. J. Nutr. 1995; 74: 649-59.

27 Fargeli RA, Wandel M. Gender differences in opinions and practices with regard to a 'healthy diet'. Appetite 1999; 32: 171-90. 